CARPATHIAN JOURNAL OF FOOD SCIENCE AND TECHNOLOGY

journal homepage: http://chimie-biologie.ubm.ro/carpathian_journal/index.html

\title{
ANTIOXIDANT, ANTIMICROBIAL ACTIVITY OF POMEGRANATE PEEL WASTES EXTRACTED IN DIFFERENT SOLVENTS AND IDENTIFICATION OF PHENOLIC COMPOUNDS WITH HPLC-DAD
}

\begin{tabular}{|c|c|}
\hline \multicolumn{2}{|c|}{ Sukru Karatas ${ }^{1 凶}$, Elif Cakir ${ }^{1}$, Munise Ustun ${ }^{1}$} \\
\hline $\begin{array}{l}{ }^{1} \text { Department of } \\
\text { tps://doi.org/10.34. }\end{array}$ & $\begin{array}{l}\text { ng, Istanbul Aydin University, PO Box 38, } 34295 \text { Küçükçekmece, } \\
\text { Istanbul, Turkey } \\
\bigotimes_{\text {karatassukru@gmail.com }} \\
\text { 1.13.1.14 }\end{array}$ \\
\hline Article history: & ABSTRACT \\
\hline $\begin{array}{l}\text { Received: } \\
\text { 22 October } 2020 \\
\text { Accepted: } \\
\quad 2 \text { February } 2021\end{array}$ & $\begin{array}{l}\text { The aim of this research was to investigate the extract of antioxidant and } \\
\text { antimicrobial properties of pomegranate peel (PP) wastes and their effect } \\
\text { on the E. coli, S. aureus, S.mutans at different concentrations of } 10-100 \% \text {. } \\
\text { Total phenolic compound substance and antioxidant modification were }\end{array}$ \\
\hline $\begin{array}{l}\text { Keywords: } \\
\text { Pomegranate peel; } \\
\text { Total phenol; } \\
\text { Antimicrobial; } \\
\text { Punicalin; } \\
\text { Pathogenic bacteria. }\end{array}$ & $\begin{array}{l}\text { inspected using Folin Ciocalteau and ABTS methods respectively. The } \\
\text { antimicrobial activity was tested on the microorganisms using diffusion } \\
\text { method and the scanning of the phenolic compounds were analyzed using } \\
\text { HPLC-DAD and the most abundant compound was estimated to be the } \\
\text { punicalin, gallic acid, ellagic acid and quercetin. The most common phenolic } \\
\text { compound was detected to bepunicalin and the highest antioxidant activity } \\
\text { was about } 821.72 \text { mmoltrolox/mg with }(60 \%) \text { acetone extract and the effect } \\
\text { on the phenol increased up to } 445.04 \text { GAEq (mg GA/g) when PP extracted } \\
\text { with ethanol, methanol and ( } 60 \%) \text { acetone. The results were evaluated and } \\
\text { statistically analyzed according to antioxidant and antimicrobial effect of } \\
\text { each extract on the E. coli, S. aureus and S.mutans which were found to } \\
\text { be the most abundant when PP extracted with }(10 \%-60 \%) \text { acetone }\end{array}$ \\
\hline
\end{tabular}

\section{Introduction}

Punicagranatum, a member of the Punicaceae family, has been known as a healing food since ancient times, and it is grown mostly in Asia, from Iran to Himaya in the Mediterranean region (Das et al., 1999; Jafri, Aslam, Javed, \& Singh, 2000; Meerts et al., 2009; Vidal et al., 2003; Viuda-Martos, Fernández-López, \& Pérez-Álvarez, 2010).

Pomegranate has positive effects on health due to anti-cancer, anti-obesity, anti-diabetic and anti-ulcerogenic properties and attracts attention (Alexandre et al., 2019; Zhu \& Liu, 2013) due to enhancing nutritional features in the human diet (Alexandre et al., 2019). Pomegranates may be consumed fresh and may be processed as industrial products like fruit juice, jelly, jam, and vinegar and forms significant amounts of by-product (Alexandre et al., 2019; Sood \& Gupta, 2015). The byproducts appear to be a source of valuable compounds (Sood \& Gupta, 2015) as pomegranate peel contains high amounts of bioactive compounds and is even a source of natural antioxidants with strong biological activity content (Akhtar, Ismail, Fraternale, \& Sestili, 2015). The flavonoids in pomegranate peel were shown to be rich in hydroxybenzoic acids and hydroxycinnamic acids. Pomegranate proteins with antimicrobial properties form a complex with sulfhydryl groups and were determined to show inhibitory effects against bacterial cell (Cristani et al., 2007; Goel, Puniya, Aguilar, \& Singh, 2005). Synthetic and natural preservatives are used to inhibit pathogenic 
organisms causing problems with food safety and to increase shelf life in the world in general. However, interest in natural preservatives has increased as synthetic preservatives cause problems in terms of health. Studies have determined that compounds in the peel sections of fruit with antimicrobial activity may prevent food degradation. Studies have shown that the extraction of active compounds in pomegranate from a variety of sections of the fruit displays variations according to the type of extraction and form of phenolic extraction (Al-Zoreky, 2009; Hegde et al., 2012; Pradeep, Manojbabu, \& Palaniswamy, 2008; Tanveer et al., 2015). Many studies have been performed about pomegranate to date; however, it is important to determine the amount and type of solvent pomegranate peel wastes to provide the highest antioxidant activity amounts and best antibacterial effect.

This study determined the total phenolic compounds, antioxidant variation with Folin Ciocalteu and ABTS methods, and antioxidant compounds with phenolic compound screening using HPLC-DAD for extracts obtained using different concentrations $(10,20,30,40,50,60$, $70,80,90$ and $100 \%$ ) of methanol, ethanol and acetone solvents. Additionally, the aim was to determine the antibacterial effects of extracts obtained with different solvents from peel wastes on food pathogens like E. coli, S. aureus and $S$. mutans with the disk diffusion method.

\section{Materials and methods}

\subsection{Materials}

\subsubsection{Pomegranate Samples}

Pomegranate samples were purchased from a local market and constituted as research material. The pomegranates were separated from peels and membrane and granulated; the grains were pressed by a juicer and kept in a deep freezer at $-18^{\circ} \mathrm{C}$ until the analysis. Peel pomegranate wastes were dried in vacuum oven at $55^{\circ} \mathrm{C}$ and dried pomegranate peels were grinded by blender and kept in a refrigerator at $40^{\circ} \mathrm{C}$ until used. In order to be able to evaluated the research results statistically was analyzed by using of Kruskall Wallis method (Hegde et al., 2012).

\subsubsection{Methods}

The extraction methods was carried out on the 30 samples of dried pomegranate peels were taken into an Erlenmeyer and extracted using of Methanol, Ethanol and Acetone (HLPC grade Merck) with dilution of $10 \%, 20 \%, 30 \%, 40 \%$, $50 \%, 60 \%, 70 \%, 80 \%, 90 \%$ and $100 \%$ solutions (Batta \& Rangaswami, 1973). Each solvent (v:v) was prepared from one gram of sample and mixed with $20 \mathrm{ml}$ of solvent then mixtures were replaced on the shaker for 24 hours at the end of that time the Erlenmeyer were removed and extracts replaced into the centrifugal tubes then centrifugated at $4000 \mathrm{rpm}$ for $5 \mathrm{mins}$. At the end of this duration, filtrations were performed through filter paper then 1 to $1.5 \mathrm{ml}$ of filtrates were taken into rotrary evaporater in order to remove the solvents from each sample then replaced into the Eppendorf tubes to indicate antimicrobial activity of the pomegratnate peel wastes extract and also to determine phenolic compounds by HPLC-DAD analysis (Fang, Zhang, \& Wang, 2007).

\subsubsection{Estimation total phenolic content (TPC)}

The content of total phenolics in the extracts was determined by spectrophotometric method at $750 \mathrm{~nm}$ according to the Folin-Ciocalteu procedure and calculated as $\mathrm{mg} / \mathrm{g}$ of gallic acid equivalents (Sellappan, Akoh, \& Krewer, 2002). Principle of the method is based on a redoxreactions, in which Folin-Ciocalteu reagent of phenolic components are came down in an alkaline environment and convert into an oxidized form then total phenolic substance.

\subsubsection{Antioxidant activity}

The method recommended by Miller and Rice-Evans (Miller, Rice-Evans, Davies, Gopinathan, \& Milner, 1993; Miller \& RiceEvans, 1997; Rice-Evans, Miller, \& Paganga, 1996) was used. This method is based on the principle $\quad$ (ABTS $^{+} \quad$ (2,2'-azinobis-(3etylbenzotiazoline-6-sulphonic acid)), ensuring nominal measurement is compared to antioxidative substance amount, kept by radical cation with standard amounts of Troloxs, which is a synthetic antioxidant (water-soluble vitamin E analog). The samples, separated depending on estimated antioxidant contents from all samples 
for antioxidant determination, were diluted with pure water at certain rates. ABTS and $4.9 \mathrm{mM}$ solvent with $14 \mathrm{mM}$ concentration and $\mathrm{K}_{2} \mathrm{~S}_{2} \mathrm{O}_{8}$ (potassium persulphate) solvent were combined at the same ratio and kept waiting in a dark place and at room temperature not less than 12-16 hours. Prepared stock solution was diluted with ethanol. For each solvents in different concentrations at the $20 \mu 1,30 \mu 1,40 \mu 1$ values, antioxidant activities were determined for 3 minutes at 30 seconds intervals. Calculations were made taking account of dilution factors.

\subsubsection{Determination of phenols with HPLC- DAD}

After extraction for phenol analysis, blowing away solvents from separated samples by rotary evaporator analysis sample were obtained. Zorbax C Column was used. Mobile phase $2.5 \%$, Acetic Acid $/ 97.5 \%$ Acetonitrile, flow rate $1 \mathrm{~mL} / 0.5 \mathrm{~mL}^{-1}$, Lichrospher Column: C18 Nucleosil column $(150 \times 4,6 \mathrm{~mm})$ were adjusted as particle size is $5 \mu \mathrm{m}$ and injection volume $20 \mu \mathrm{L}$. A scan was made at $280 \mathrm{~nm}$ and $360 \mathrm{~nm}$ wavelengths. Preparing 50, 60, $80,100,120$, and $150 \mathrm{ppm}$, standard from stock Gallic acid standard by methanol, calibration curve was drawn. For quercetin, 40, 50, 60, and 100 ppmstandards of stock solvent were prepared by methanol and calibration curve was drawn. For catechin 100, 120, 150, 200, and $250 \mathrm{ppm}$ standards were prepared by water and calibration curve was drawn.

\subsubsection{Antimicrobial activity determination}

After extraction for antimicrobial activity determination, separated samples were used. 1 loop was received from the stock culture, stored at $-80{ }^{\circ} \mathrm{C}$ and put into the tube, containing $9 \mathrm{ml}$ nutrient broth. It was left for incubation at $37^{\circ} \mathrm{C}$ for 24 hours. At the end of the duration, $100 \mu 1$ of culture, called subculture was put into the tube, containing nutrient broth and left for incubation for 14-15 hours. Escherichia coli, Streptococcus mutans, Staphylococcus aureus were used in the study (Dehkordi, Basti, Gandomi, Misaghi, \& Rahimi, 2019). EMB and PCA were used as medium. For $S$. mutans and $S$. aureus $\mathrm{PCA}$, for E. coli $\mathrm{EMB}$, was used as a medium. Well diffusion method was used in the studies. Pour plate and spread plate methods were used. Since pour plate did not give result for $E$. coli, spread plate method was used. Each petri was divided into 4 equal pieces. And a well was opened into each divided part. Separated $50 \mu 1$ sample solvent was put into each well and left for incubation

\section{Results and discussions}

\subsection{Quantification of bioactive compounds} Please complete

\subsubsection{Total amount of phenolic substance}

Total phenol content for ethanol, methanol and acetone in different concentrations are shown in Fig. 1A.

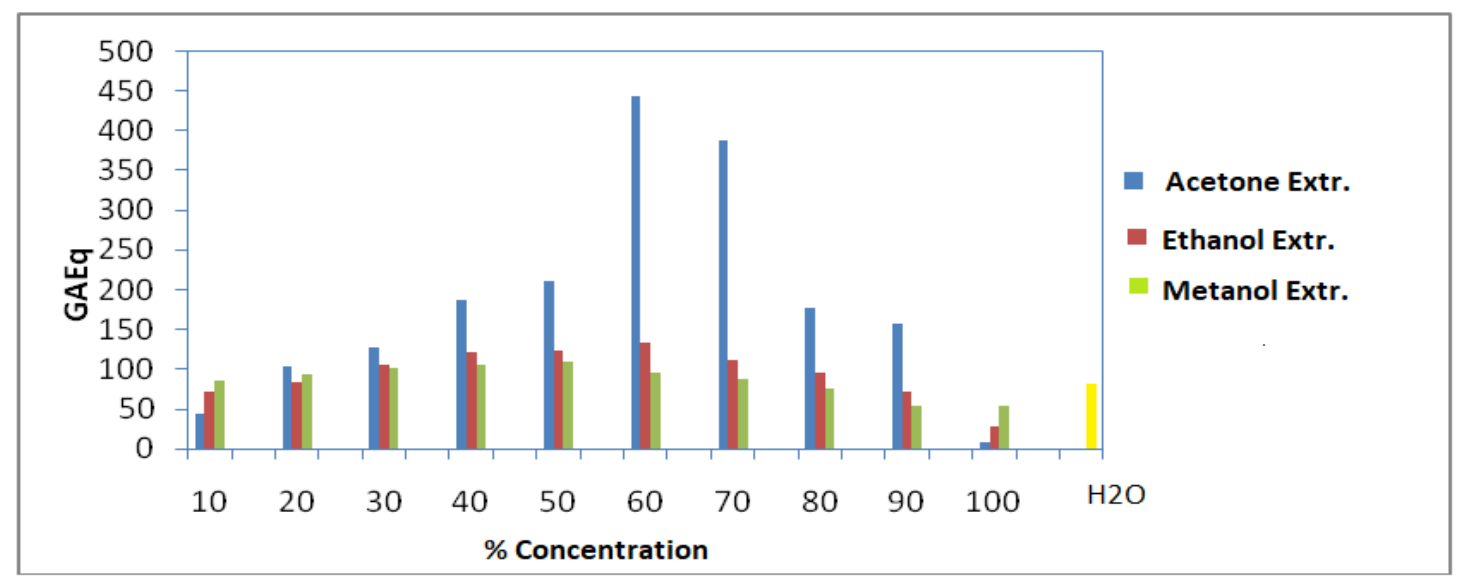

Figure1(A) Total phenol content GAEq:mg/g of gallic acid equivalent 
When the results obtained from spectrometric measurements are examined, it is seen that acetone has the highest effect, making available total phenol content in all extractions and solvent types. The data from total phenol content of pomegranate applied Kruskal-Wallis test (Asymp.Sig. $<0,05$ ) is examined, it is determined that the highest effect is on acetone and respectively on the extracts obtained from ethanol and methanol extractions. In view of the findings, which we obtained at the end of the study, while especially $60 \%$ acetone solvent 445.012 GAEq (mg/g of gallic acid equivalent) affects the total phenol highly, it is determined that this is lower for ethanol and methanol. Kinetic measurements of ethanol, methanol and acetone in certain time periods are shown in Fig. $1 \mathrm{~B}$.

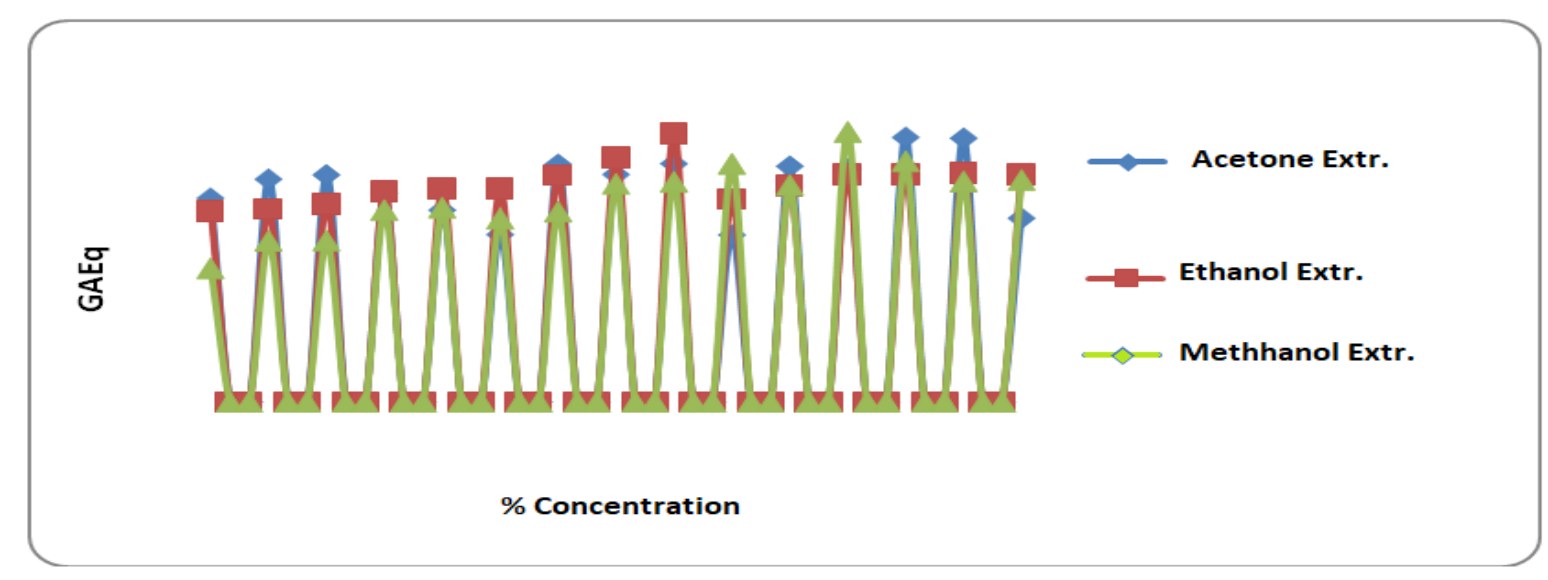

Figure 1(B). Kinetic measurements for total phenol

When the results obtained from spectrophotometric measurements are examined, it is seen that the kinetic measurement results for 3 solvents are close. In the extracts obtained from extraction against time, when total phenol effect is observed, it is seen that the extraction time does not have a significant effect on the efficiency.

\subsection{Antioxidant activity}

Antioxidant activity effects in ethanol, acetone and methanol extractions are shown by Figures 2A, 2B, and 2C, respectively. The results of spectrophotometric measurements demonstrated that antioxidant activities in all solvents are very high. The highest effect is measured 254228 aox in the extract obtained from $60 \%$ ethanol extraction and 143154 aox in the extract obtained from $40 \%$ methanol extraction. Meanwhile, antioxidant activities in ethanol, methanol and acetone in different concentrations are shown in Figure 3. The results demonstrated that antioxidant activity of acetone in all extractions and solvent types are the highest one. When the results obtained from the ethanol, methanol, acetone activities were considered it was seen that the aox activity given was high. In addition, it was estimated that aox activities were reduced depending on the duration of aox activity. When this data is applied to the Kruskal-Wallis test (Asymp. Sig. $<0,05)$ and examined, it was determined that the highest effect is on the acetone, ethanol and methanol extracts respectively. The highest efficiency is estimated as $821.72 \mathrm{mmol}$ trolox $/ \mathrm{mg}$ in the $60 \%$ acetone extraction. These results indicated that the antioxidant level of pomegranate was high and they were similar with the previous studies (Mertens-Talcott, Jilma-Stohlawetz, Rios, Hingorani, \& Derendorf, 2006). In their study, Singh et al. (Singh, Chidambara Murthy, \& Jayaprakasha, 2002) determined that in their extraction using ethyl acetate, methanol and water from pomegranate peels and seeds, the peels showed 
$83 \%$ and $81 \%$ antioxidant activity at $50 \mathrm{ppm}$ with methanol extraction.

The average syneresis values of probiotic yoghurt samples were given in Table 1. On the $30^{\text {th }}$ minute of the measurements, the highest syneresis rate was determined in P2 sample on the $1^{\text {st }}$ day $(18.50 \mathrm{~mL})$, while the lowest syneresis rate was in $\mathrm{K}$ sample $(12 \mathrm{~mL})$ on the $14^{\text {th }}$ and $21^{\text {st }}$ days. As a result of the analysis of variance, the difference between the storage days were significant $(p<0.05)$. In the samples containing rice milk, the syneresis rate was lower in P3, compared to the two other samples. Among all the results, difference between P1 sample and $\mathrm{K}$ sample was not significant $(p>0.05)$. On the $60^{\text {th }}$ minute of the measurements, the highest syneresis rate was in P2 sample on the $1^{\text {st }}$

\subsection{Antimicrobial activity determination}

Antimicrobial effects for extractions of different acetone concentrations are shown in Table 1. Statistically significant different zone diameters were determined on the E.coli, S.aureus and S.mutans according to the type of extraction with different concentrations of ethanol, methanol and acetone. When antimicrobial effects for extractions of different ethanol concentrations are examined, it is determined that E.coli created a zone having an average $21.5 \mathrm{~mm}$ diameter, acetone average $20,5 \mathrm{~mm}$ and methanol $13,5 \mathrm{~mm}$ as a

result of the first measurement in $10 \%$ ethanol extraction. While the antibacterial effect of acetone on E.coli was higher than 10-40\%, ethanol and methanol were found to be statistically similar at these rates. Zone diameter
$14 \mathrm{~mm}$ at $50 \%$ extraction while it was measured as $10 \mathrm{~mm}$ at $100 \%$ extraction. When the table is examined, it is observed that while ethanol concentration increases, zone diameters gradually decrease. The zone diameter decreased due to the increase in acetone concentration as well. In methanol extraction, the zone diameter was found to be statistically similar up to $70 \%$, and the highest zone diameter was determined at $50 \%$. The $90 \%$ and $100 \%$ methanol extraction zone diameter was found to be higher than ethanol and acetone extraction at the same rates, and it was statistically significant. When the zone diameters were compared on the $S$. aureus pathogen bacteria, as the amount of ethanol, acetone, and methanol increased, the zone diameters decreased. The highest effect in ethanol was determined at 10$30 \%$, in acetone $70-80 \%$ and in methanol at $10-$ $40 \%$. The highest antibacterial effect on $S$. mutans was determined in acetone extraction, and the lowest effect was seen in ethanol. There was no antimicrobial effect against $S$. mutans above $50 \%$ methanol extraction. In a study on the antibacterial effect of pomegranate peel on methanol extraction, it was reported that it exhibited antibacterial activity against $L$. monocytogenes, $Y$. enterocolitica, E. coli and $S$. aureus (Prashanth, Asha, \& Amit, 2001).It has been observed that $80 \%$ methanol extraction is an active inhibitor against pathogenic bacteria such as L. monocytogenes, E. coli, S. aureus and $Y$. enterocolitica in the process of extraction with water, methanol and ethyl alcohol by traditional methods (Al-Zoreky, 2009). 


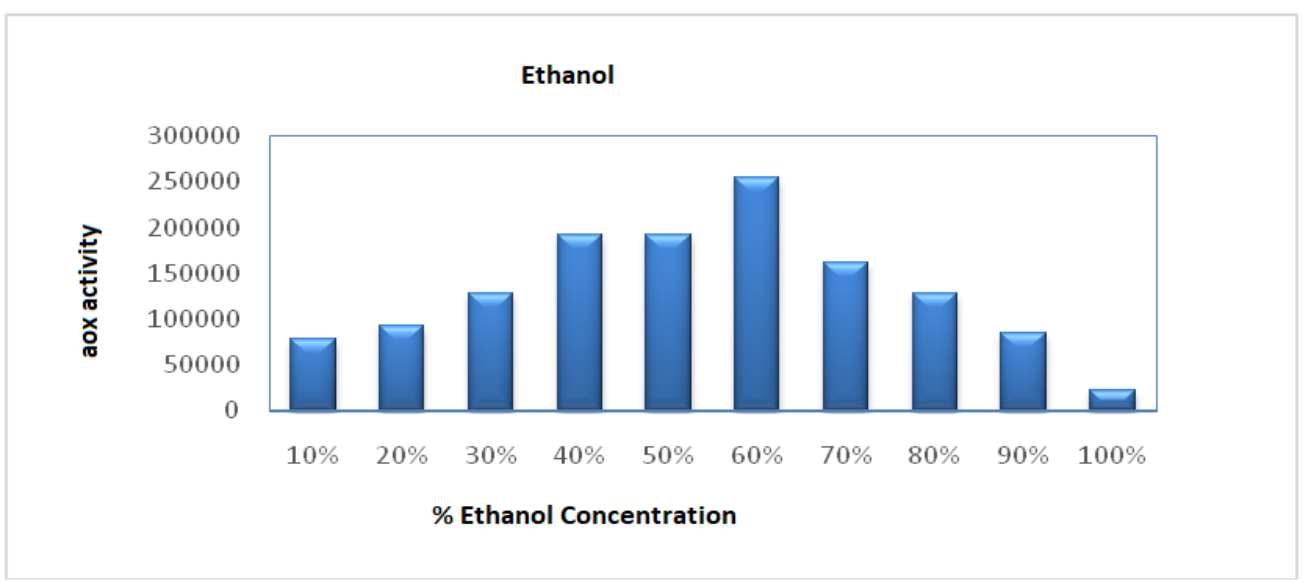

Figure 2A. Aox activity in ethanol extraction in relation to the Trolox TM standard concentration

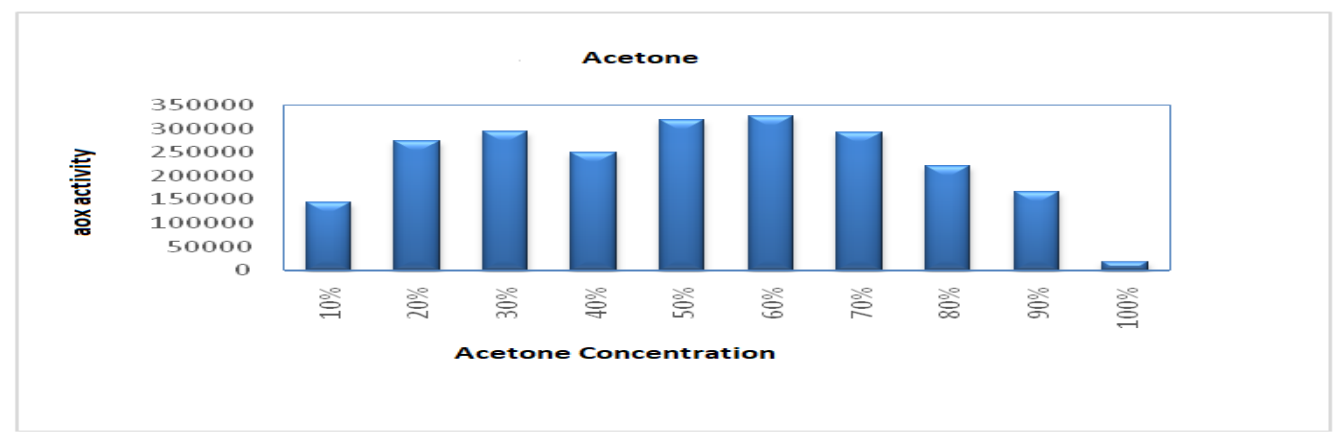

. Figure 2B.Aox activity in acetone extraction in relation to the Trolox TM standard concentration

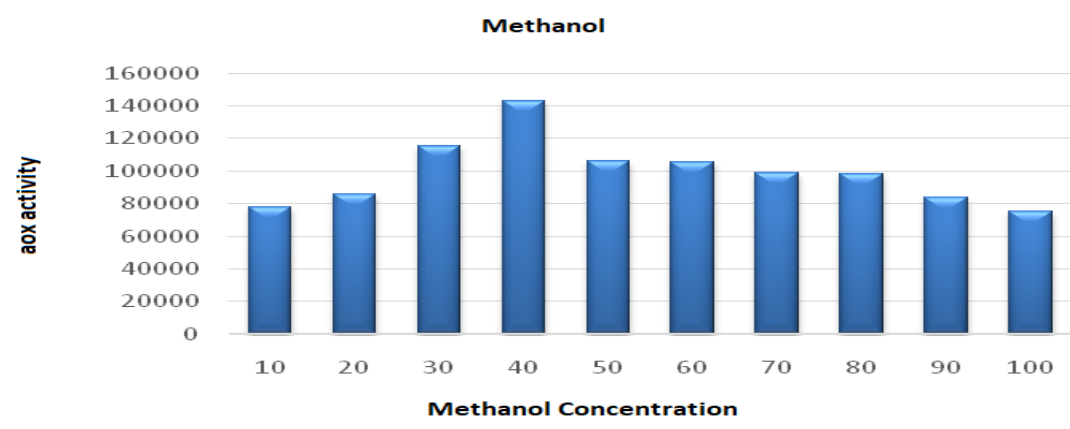

Figure 2C. Aox activity in methanol extraction in relation to the Trolox TM standard concentration 


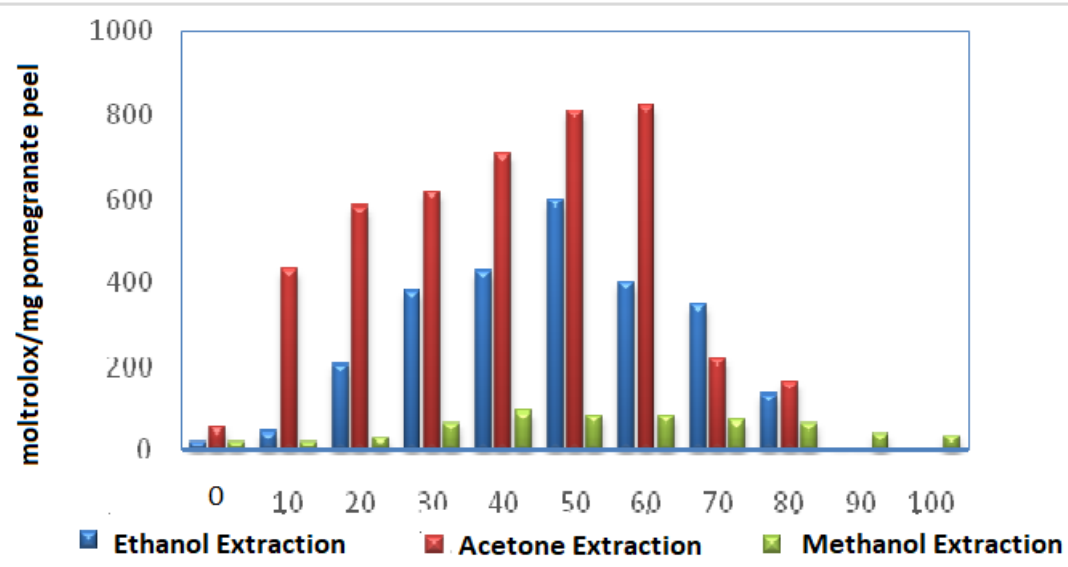

Figure 3.Aox activity in ethanol, acetone, and methanol extraction in relation to the Trolox TM standard concentration

\subsection{Determination of phenols with HPLC- DAD}

As shown on the Fig. 3 at $280 \mathrm{~nm}$ performed by us according to the results obtained from HPLC chromatogram in 50\% acetone extraction, components, which cover the largest area are Punicalagin derivatives. In addition to this, gallic acid, punicalin-A and Ellagic acid derivatives follow this. Similarly the study of Nasr et.al (Nasr, Ayed, \& Metche, 1996) quantitatively determined ellagic tannins and gallic and elagic acids in the peels of Tunisian pomegranate.

Table 1. Antimicrobial Effects of omegranate Peel Against Some Foodborne Bacteria in Extracts of Different Solvents ( $\mathrm{mm}$ zone diameter)

\begin{tabular}{|c|c|c|c|c|c|c|c|c|c|}
\hline \multirow[b]{2}{*}{$\%$} & \multirow[b]{2}{*}{ Etanol } & \multicolumn{3}{|c|}{ E.coli } & \multicolumn{3}{|c|}{ S.aureus } & \multicolumn{2}{|c|}{ S.mutans } \\
\hline & & Aseton & Methanol & Etanol & Aseton & Methanol & Etanol & Aseton & Methanol \\
\hline 10 & $21.5 \pm 0.7^{\mathrm{Aa}}$ & $20.5 \pm 0.7^{\mathrm{Ca}}$ & $13.5 \pm 0.7^{\mathrm{Bb}}$ & $18.5 \pm 0.7^{\mathrm{Ba}}$ & $14 \pm 0.0^{\mathrm{Bb}}$ & $12.5 \pm 2.1^{\mathrm{ABCb}}$ & $1 \pm 0.0^{\mathrm{Bc}}$ & $17.5 \pm 0.5^{\mathrm{Aa}}$ & $12.5 \pm 2.1^{\mathrm{Ab}}$ \\
\hline 20 & $19 \pm 2.8^{\mathrm{Aab}}$ & $24 \pm 0.0^{\mathrm{Aa}}$ & $16.5 \pm 0.7^{\mathrm{ABb}}$ & $22.5 \pm 0.7^{\mathrm{Aa}}$ & $14 \pm 0.0^{\mathrm{Bb}}$ & $15 \pm 0.0^{\mathrm{Ab}}$ & nd & $18.5 \pm 0.5^{\mathrm{Aa}}$ & $15 \pm 0.0^{\mathrm{Ab}}$ \\
\hline 30 & $19 \pm 2.8^{\mathrm{Aab}}$ & $22 \pm 0.0^{\mathrm{BCa}}$ & $14.5 \pm 0.7^{\mathrm{ABb}}$ & $13.5 \pm 0.7^{\mathrm{Ca}}$ & $14 \pm 0.0^{\mathrm{Ba}}$ & $13.5 \pm 0.7^{\mathrm{ABCa}}$ & nd & $15 \pm 3^{\mathrm{ABCa}}$ & $13.5 \pm 0.7^{\mathrm{Aa}}$ \\
\hline 40 & $15 \pm 0.0^{\mathrm{Bb}}$ & $23 \pm 1.4^{\mathrm{ABa}}$ & $16 \pm 1.4^{\mathrm{ABb}}$ & $10 \pm 0.0^{\mathrm{DEa}}$ & $14 \pm 1.4^{\mathrm{Ba}}$ & $12.5 \pm 3.5^{\mathrm{ABCa}}$ & nd & $10 \pm 2^{\mathrm{CDa}}$ & $13.5 \pm 2.1^{\mathrm{Aa}}$ \\
\hline 50 & $18.5 \pm 0.7^{\mathrm{Aa}}$ & $15 \pm 0.0^{\mathrm{Db}}$ & $17.5 \pm 0.7^{\mathrm{Aa}}$ & $12 \pm 2.8^{\mathrm{CDa}}$ & $9.5 \pm 0.7^{\mathrm{Da}}$ & $11 \pm 1.4^{\mathrm{BCa}}$ & nd & $9.5 \pm 1.5^{\mathrm{D}}$ & nd \\
\hline 60 & $11 \pm 0.0^{\mathrm{Cb}}$ & $16 \pm 0.0^{\mathrm{Da}}$ & $16.5 \pm 0.7^{\mathrm{ABa}}$ & $10 \pm 0.0^{\mathrm{DEb}}$ & $11 \pm 0.0^{\mathrm{Cb}}$ & $14 \pm 1.4^{\mathrm{ABa}}$ & nd & $17.5 \pm 0.5^{\mathrm{A}}$ & nd \\
\hline 70 & $13 \pm 1.4^{\mathrm{BCc}}$ & $14 \pm 0.0^{\mathrm{Ab}}$ & $16.5 \pm 0.7^{\mathrm{ABa}}$ & $10.5 \pm 0.7^{\mathrm{Db}}$ & $16 \pm 0.0^{\mathrm{Aa}}$ & $11 \pm 1.4^{\mathrm{BCb}}$ & nd & $17.5 \pm 0.5^{\mathrm{A}}$ & nd \\
\hline 80 & $6.5 \pm 0.7^{\mathrm{Dc}}$ & $14 \pm 0.0^{\mathrm{Aa}}$ & $14 \pm 1.4^{\mathrm{Bb}}$ & $7,5 \pm 0.7^{\mathrm{EFc}}$ & $17 \pm 0.0^{\mathrm{Aa}}$ & $10.5 \pm 0.7^{\mathrm{BCb}}$ & nd & $13.5 \pm 1.5^{\mathrm{ABCD}}$ & nd \\
\hline 90 & $4.5 \pm 0.7^{\mathrm{Db}}$ & $8 \pm 1.4^{\mathrm{Eab}}$ & $13.5 \pm 3.5^{\mathrm{Ba}}$ & $7 \pm 1.4^{\mathrm{Fa}}$ & $10 \pm 1.4^{\mathrm{CDa}}$ & $11.5 \pm 2.1^{\mathrm{ABCa}}$ & $10 \pm 0.0^{\mathrm{A}}$ & $16 \pm 3^{\mathrm{AB}}$ & nd \\
\hline 100 & $5 \pm 0.0^{\mathrm{Dc}}$ & $9 \pm 1.4^{\mathrm{Eb}}$ & $14 \pm 1.4^{\mathrm{Ba}}$ & $6.5 \pm 0.7^{\mathrm{Fa}}$ & $2 \pm 0.0^{\mathrm{Eb}}$ & $10 \pm 0.0^{\mathrm{Ca}}$ & $10 \pm 0.0^{\mathrm{A}}$ & $11.5 \pm 0.5^{\mathrm{BCD}}$ & nd \\
\hline
\end{tabular}

A-E: Values with different letters in the same column differ statistically significantly $(\mathrm{P}<0.05)$. a-c: Values with different letters in the same row differ statistically significantly $(\mathrm{P}<0.05)$, nd:not detected 


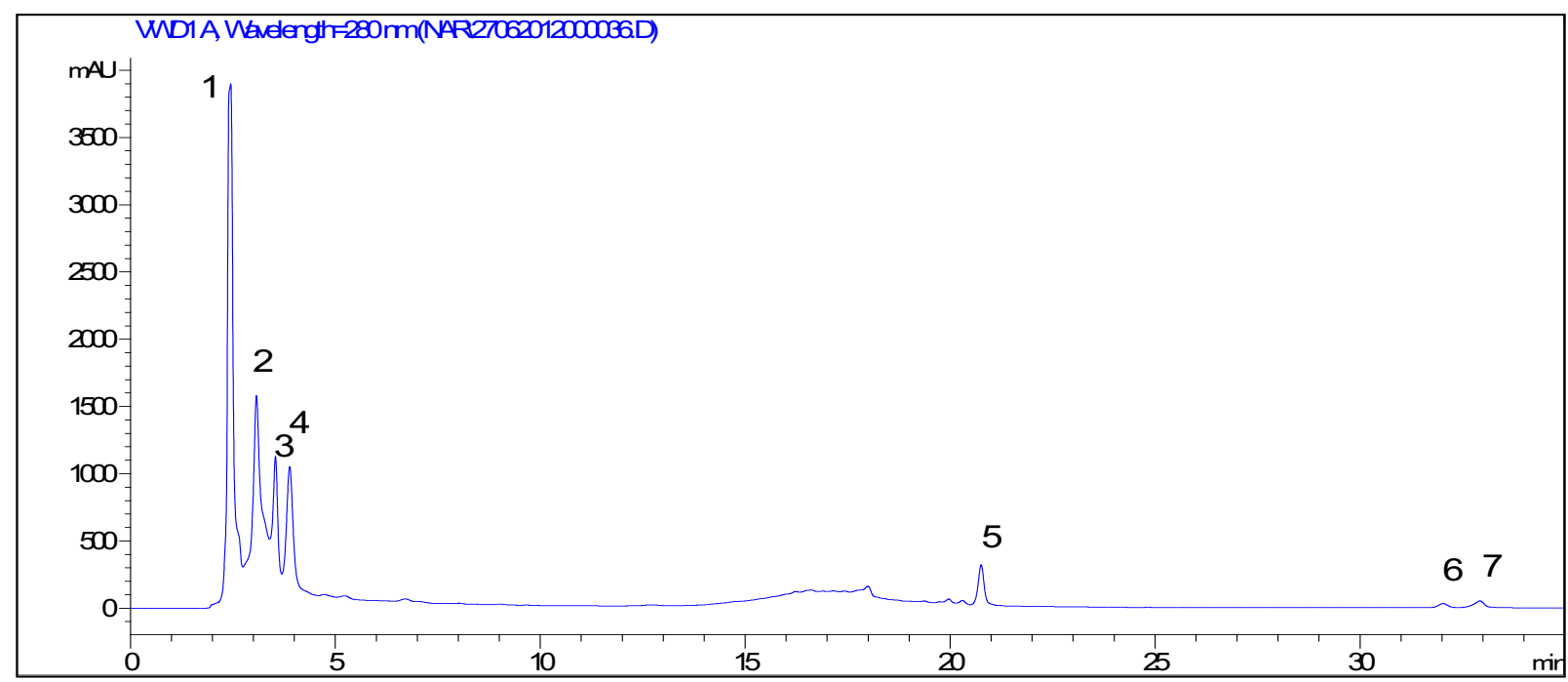

Figure 4. HPLC chromatogram of phenolic components in pomegranate peel with adding 400ppm standard gallic acid in 50\% acetone extraction (1-2 Punicalagin derivatives, 3- Gallic acid, 4- PunicalinA, 5-Ellagic acid derivatives, 6-Punicalagin-B).

\section{Conclusions}

This research studied the total phenolic content, antioxidant activity, antimicrobial activity and phenolic compounds from pomegranate peel using solvent extractions methods by methanol, ethanol and acetone with concentrations of $10-100 \%(\mathrm{v} / \mathrm{v})$. Total phenolic contents were determined by Folin Ciocalteau method and results showed that maximum total phenol content was 445.012GAEq $(\mathrm{mg} / \mathrm{g}$ of gallic acid equivalent) at $60 \%$ acetone solvent. Antioxidant activities were calculated by ABTS method and results demonstrated that highest antioxidant activity was about 821.72 mmoltrolox/mg with (60\%) acetone extract. Also, HPLC-DAD analysis showed that the most abundant phenolic compounds were the punicalagin, gallic acid, ellagic acid and quercetin. The highest zone diameters against E.coli and S.mutans pathogen bacteria were determined in acetone extraction, and the highest zone diameter against S.aureuswas determined in ethanol extraction. The antimicrobial effects of pomegranate peel extract on the E. coli, S. aureus, S.mutans showed that the antimicrobial effect is seen on the E. coli from the acetone solvent. Thus, acetone can be considered as a useful solvent for extraction of phenolic compound from pomegranate peel to approach antioxidant and antimicrobial effect of them as a preventive and therapeutic in human health.

\section{References}

Akhtar, S., Ismail, T., Fraternale, D., \& Sestili, P. (2015). Pomegranate peel and peel extracts: Chemistry and food features. Food chemistry, 174, 417-425.

Al-Zoreky, N. (2009). Antimicrobial activity of pomegranate (Punica granatum L.) fruit peels. International journal of food microbiology, 134(3), 244-248.

Alexandre, E. M., Silva, S., Santos, S. A., Silvestre, A. J., Duarte, M. F., Saraiva, J. A., \& Pintado, M. (2019). Antimicrobial activity of pomegranate peel extracts performed by high pressure and enzymatic assisted extraction. Food research international, 115, 167-176.

Batta, A., \& Rangaswami, S. (1973). Crystalline chemical components of some vegetable drugs. Phytochemistry.

Cristani, M., D'Arrigo, M., Mandalari, G., Castelli, F., Sarpietro, M. G., Micieli, D., Trombetta, D. (2007). Interaction of four monoterpenes contained in essential oils with model membranes: implications for their antibacterial activity. Journal of agricultural and food chemistry, 55(15), 6300-6308. 
Das, A. K., Mandal, S. C., Banerjee, S. K., Sinha, S., Das, J., Saha, B., \& Pal, M. (1999). Studies on antidiarrhoeal activity of Punica granatum seed extract in rats. Journal of ethnopharmacology, 68(1-3), 205-208.

Dehkordi, S. F., Basti, A., Gandomi, H., Misaghi, A., \& Rahimi, E. (2019). Pathogenic Staphylococcus aureus in hospital food samples; prevalence and antimicrobial resistance properties (Retraction of Vol 38, art no E12501, 2018): WILEY 111 RIVER ST, HOBOKEN 07030-5774, NJ USA.

Fang, Z., Zhang, M., \& Wang, L. (2007). HPLCDAD-ESIMS analysis of phenolic compounds in bayberries (Myrica rubra Sieb. et Zucc.). Food chemistry, 100(2), 845-852.

Goel, G., Puniya, A., Aguilar, C., \& Singh, K. (2005). Interaction of gut microflora with tannins in feeds. Naturwissenschaften, 92(11), 497-503.

Hegde, C. R., Madhuri, M., Swaroop, T. N., Das, A., Bhattacharya, S., \& Rohit, K. (2012). Evaluation of antimicrobial properties, phytochemical contents and antioxidant capacities of leaf extracts of Punica granatum L. ISCA J. Biological Sci, 1(2), 32-37.

Jafri, M., Aslam, M., Javed, K., \& Singh, S. (2000). Effect of Punica granatum Linn.(flowers) on blood glucose level in normal and alloxan-induced diabetic rats. Journal of ethnopharmacology, 70(3), 309314.

Meerts, I., Verspeek-Rip, C., Buskens, C., Keizer, H., Bassaganya-Riera, J., Jouni, Z.,Van de Waart, E. (2009). Toxicological evaluation of pomegranate seed oil. Food and Chemical Toxicology, 47(6), 10851092.

Mertens-Talcott, S. U., Jilma-Stohlawetz, P., Rios, J., Hingorani, L., \& Derendorf, H. (2006). Absorption, metabolism, and antioxidant effects of pomegranate (Punica granatum L.) polyphenols after ingestion of a standardized extract in healthy human volunteers. Journal of agricultural and food chemistry, 54(23), 8956-8961.

Miller, N. J., Rice-Evans, C., Davies, M. J., Gopinathan, V., \& Milner, A. (1993). A novel method for measuring antioxidant capacity and its application to monitoring the antioxidant status in premature neonates. Clinical science, 84(4), 407-412.

Miller, N. J., \& Rice-Evans, C. A. (1997). Factors influencing the antioxidant activity determined by the ABTS $\bullet+$ radical cation assay. Free radical research, 26(3), 195199.

Nasr, C. B., Ayed, N., \& Metche, M. (1996). Quantitative determination of the polyphenolic content of pomegranate peel. Zeitschrift für Lebensmittel-Untersuchung und Forschung, 203(4), 374-378.

Pradeep, B., Manojbabu, M., \& Palaniswamy, M. (2008). Antibacterial activity of Punica granatum L. against gastro intestinal tract infection causing organisms. Ethnobotanical leaflets, 2008(1), 143.

Prashanth, D., Asha, M., \& Amit, A. (2001). Antibacterial activity of Punica granatum. Fitoterapia, 72(2), 171-173.

Rice-Evans, C. A., Miller, N. J., \& Paganga, G. (1996). Structure-antioxidant activity relationships of flavonoids and phenolic acids. Free radical biology and medicine, 20(7), 933-956.

Sellappan, S., Akoh, C. C., \& Krewer, G. (2002). Phenolic compounds and antioxidant capacity of Georgia-grown blueberries and blackberries. Journal of agricultural and food chemistry, 50(8), 2432-2438.

Singh, R., Chidambara Murthy, K., \& Jayaprakasha, G. (2002). Studies on the antioxidant activity of pomegranate (Punica granatum) peel and seed extracts using in vitro models. Journal of agricultural and food chemistry, 50(1), 81-86.

Sood, A., \& Gupta, M. (2015). Extraction process optimization for bioactive compounds in pomegranate peel. Food Bioscience, 12, 100-106. 
Tanveer, A., Farooq, U., Akram, K., Hayat, Z., Shafi, A., Nazar, H., \& Ahmad, Z. (2015). Pomegranate extracts: A natural preventive measure against spoilage and pathogenic microorganisms. Food Reviews International, 31(1), 29-51.

Vidal, A., Fallarero, A., Peña, B. R., Medina, M. E., Gra, B., Rivera, F., Vuorela, P. M. (2003). Studies on the toxicity of Punica granatum L.(Punicaceae) whole fruit extracts. Journal of ethnopharmacology, 89(2-3), 295-300.

Viuda-Martos, M., Fernández-López, J., \& Pérez-Álvarez, J. (2010). Pomegranate and its many functional components as related to human health: a review. Comprehensive Reviews in Food Science and Food Safety, 9(6), 635-654.

Zhu, C., \& Liu, X. (2013). Optimization of extraction process of crude polysaccharides from Pomegranate peel by response surface methodology. Carbohydrate polymers, 92(2), 1197-1202. 